\title{
Encyclopedia of Tourism
}



Jafar Jafari • Honggen Xiao

Editors

\section{Encyclopedia of Tourism}

With 211 Figures and 6 Tables

Springer Reference 


\section{Editors}

Jafar Jafari

University of Wisconsin-Stout

Menomonie, USA
Honggen Xiao

The Hong Kong Polytechnic University

Hong Kong, China

ISBN 978-3-319-01383-1

ISBN 978-3-319-01384-8 (eBook)

ISBN 978-3-319-01385-5 (print and electronic bundle)

DOI 10.1007/978-3-319-01384-8

Library of Congress Control Number: 2016936094

(C) Springer International Publishing Switzerland 2016

This work is subject to copyright. All rights are reserved by the Publisher, whether the whole or part of the material is concerned, specifically the rights of translation, reprinting, reuse of illustrations, recitation, broadcasting, reproduction on microfilms or in any other physical way, and transmission or information storage and retrieval, electronic adaptation, computer software, or by similar or dissimilar methodology now known or hereafter developed.

The use of general descriptive names, registered names, trademarks, service marks, etc. in this publication does not imply, even in the absence of a specific statement, that such names are exempt from the relevant protective laws and regulations and therefore free for general use.

The publisher, the authors and the editors are safe to assume that the advice and information in this book are believed to be true and accurate at the date of publication. Neither the publisher nor the authors or the editors give a warranty, express or implied, with respect to the material contained herein or for any errors or omissions that may have been made.

Printed on acid-free paper

This Springer imprint is published by SpringerNature

The registered company is Springer International Publishing AG Switzerland. 


\section{Introduction}

While the genesis of today's worldwide tourism is to be found in historical records, its establishment as a formal academic field among anglophone scholars can only be traced to the twentieth century. In the 1970s, tourism was framed as "a study of man away from his usual habitat, of the industry which responds to his needs, and of the impacts that both he and the industry have on the host sociocultural, economic, and physical environments" (Annals of Tourism Research editorial). Since the 1990s, this field has significantly unfolded in many directions, with the resulting scientification treatments conveying the epistemological reflections of its studies.

The evolution of tourism research foci may be condensed into advocacy, cautionary, adaptancy, knowledge-based, and public platforms, each of which has added historical depth and texture to the understanding of tourism both as a field of study and as an industry. The latest platform calls for the formation of a public stance that can help tourism assume its legitimate position - side by side with other institutions and industries, in both local and global circles - and enjoy the support it deserves. In turn, this journey serves as path for tourism education, research, and the advancement of knowledge.

The edited 2009 symposium volume of the International Academy for the Study of Tourism identifies a number of patterns in the evolution of tourism research. First, the growth of tourism studies has been accompanied by an increase in a wide range of investigated topics. Second, while the nature and extent of changes vary, the overall picture that emerges is one of continuity and incremental change, with little evidence of any major paradigm shift. Third, the growth of tourism research appears not to have been driven by the pursuit of core questions under the umbrella of a unifying set of theories, leading to an unstructured and fragmented body of knowledge. Essentially, as the field moves on, its community grows to encompass new networks such as the mobilities paradigm, critical tourism studies, "new" tourism research, and the tourism education futures initiative.

More specifically, the expansion of this multidisciplinary landscape of tourism knowledge has been accompanied over the years by a phenomenal growth of its research community worldwide in terms of the large number of higher education and research institutions at universities, proliferations of academic journals and publications, rapid increase in the number of associations and conferences, as well as the diverse sources of funding for its investigations. It is quite evident that tourism research is now being conducted 
throughout the world, not only by (or within) its own circles but also in the whole array of disciplines encompassing the social sciences, business and economics, humanities, natural sciences, and even engineering. This global disciplinary rooting is reflected in four volumes published in the Tourism Social Science Series containing biographical chapters of some 60 known scholars in this field, as well as the large number of authors from around the world who have contributed to this Springer edition.

\section{Encyclopedia of Tourism}

As a genre that features a representative coverage of research topics or platforms, a multidisciplinary encyclopedia is viewed as a landmark in the knowledge development of a field of study. Notably, in an era facilitated by internet technology in disseminating research and by web-based search engines in retrieving information, the value of, and the need for, developing an authoritative encyclopedia that is also retrievable online is all the more apparent. Compared to the fully web-based Wikipedia, editable online by "pseudonyms" through user accounts, a reviewed and edited encyclopedia often stands out due to the authority of its text resulting from the expertise of invited authorship and the quality control exerted by reviewers and editors.

The first edition of the Encyclopedia of Tourism, after 5 years in the making, was published by Routledge in 2000 . Immediately after its appearance, the edition was appraised by peers as a chronicle of tourism scholarship as well as a demonstration of the leadership shown to orchestrate the efforts of hundreds of contributors and a multidisciplinary editorial team to bring the project to fruition. Nonetheless, the evolution of the field since its publication quickly made the need to develop a new edition self-evident.

To better serve the academic community with the current state of knowledge, the Springer Encyclopedia of Tourism, this time published both in electronic and print formats, is designed as a new tome in its own right. Due to copyright concerns, all entries included in this edition are new contributions, reviewed to make sure that their contents incorporate the latest in knowledge development since the turn of the century.

The entry list of the Springer edition was derived from a number of sources, including the Routledge version itself featuring 1,024 headwords; the cumulative subject index (1973-2012) of Annals of Tourism Research with 888 primary-level subject headwords, along with 1,100 secondary-level sub-headwords; and recommendations and community inputs through TRINET postings, as well as solicitation opportunities as noted in the Acknowledgments. Together, these and other inputs have resulted in the updated headword list, while leaving out some featured in the prior edition. During this process, many earlier headwords were further combined or integrated in order to arrive at the current inventory.

While essential topics have been retained from the first edition, a number of changes have been introduced in the current edition. Here, the latest UN member states are featured as "country" entries, while geographic areas under dispute or territories without UN recognition are not included. A few 
"world region" entries in line with UNWTO program designation are also introduced. The previously individual or separate entries on major tourism journals (such as Annals of Tourism Research and Journal of Travel Research) and organizations or associations (AIEST or TTRA) are now abstracted into synthesized entries, with the exception of the International Academy for the Study of Tourism and the UNWTO, which stand as leading entities in tourism research and practice.

In light of the multidisciplinary nature of tourism research and scholarship, critical social science concepts and business/management aspects have received ample attention in this edition. Emphasis is also placed on adding new entries in relation to tourism development and corresponding theories explaining them. Disciplinary domains (such as anthropology, ecology, economics, geography, management, marketing, psychology, and sociology) and tourism-related fields (including hospitality, leisure, park, and recreation) are kept as core headwords in order to acknowledge the multidisciplinarity of scholarship and multisector operation of tourism; nonetheless, affixations out of these core headwords are kept to the minimum.

In principle, the accumulation of knowledge, new research themes, changing niche products and markets, the application of innovative methods, as well as issues facing tourism research and practice after the turn of the millennium are reflected in the Springer edition. This encyclopedia is a registry of explicit tourism knowledge based on published research. New concepts or innovative terms yet to be adequately "grounded" in the research literature are to be first directed to tourism journals prior to their maturation for possible inclusion in any future edition(s) of the encyclopedia. In total, an entry list featuring 700 headwords was identified and commissioned.

To involve as many worldwide authors as possible, the new encyclopedia allowed one entry per author (or two entries on coauthorship basis, with a few unavoidable exceptions). Authorship invitations were by expertise of an entry subject. In general, due to the nature of this reference source and its intended readership, authors from academic institutions outnumber nonacademic contributors, $95 \%$ versus $5 \%$, respectively. However, according to a recent equality report, the encyclopedia did better in gender representation, with $36 \%$ of authors female and $64 \%$ male - a noticeably higher proportion of the former in contrast to other existing academic memberships. For "country" entries, joint authorship was favored, preferably one from the country itself. In the case of "world region" entries, coauthorships with a UNWTO colleague from the corresponding regional program were sought. In addition, authors from inadequately represented world regions, such as Africa, Latin America, and Pacific Island States, were invited to contribute to entry development either individually or on coauthorship basis. In total, 766 authors from 113 countries are featured in this edition of the encyclopedia.

Despite these intended efforts, the purpose of Encyclopedia of Tourism remains unchanged: to act as a guide and updated source of reference to a wide range of basic definitions, theories and concepts, disciplines and fields of studies, themes and issues, methods and approaches, products and sectors, organizations and associations, media and publications, as well as countries and world regions contributing to, or embraced by, tourism in its disparate 
manifestations. Two principles have guided the development of this new edition. One is to produce a comprehensive and updated reference source in tourism through adding new subjects as entries, updating and refining entry contents, and improving the overall presentation and usefulness of the volume as a whole. Two, the new edition is more comprehensive in subject coverage, and more international and culturally diverse in its authorship team than the first version. Its editorial body, representing all continents, consists of nine associate editors and two resource editors, who shaped the present landscape of tourism knowledge as represented in this edition.

\section{Structure and Contents}

The encyclopedia entries have three lengths: $500 \pm 25,1,000 \pm 50$, and $2,000 \pm 100$ words. A few entries are slightly higher or lower because of miscommunication among coeditors, associate editors, and/or the authors and were eventually accepted for the sake of expediency.

Structurally, each entry consists of its headword title, a brief definitional introduction, discussion, and prospective closure, plus a list of three to five "see-also" cross-references to other related or relevant entries in the encyclopedia. Style guidelines and model entries were published on the encyclopedia website. Differentiating by length, 500 -word entries bear no headings in the text and include only three to five textually cited references, whereas 1,000 and 2,000-word entries are subdivided with section headings and have five to seven and seven to ten references, respectively.

Entries can be grouped into nine categories according to content: Concept/ theory; discipline/field of study; country/region; issue-based; method/methodology; product; sector; organization/association; and journal/publication/ media. More specifically, concept/theory and discipline entries chart the origin and evolution of their subjects or knowledge domains, including related subdisciplinary areas, key tenets, definition(s), possible shifts, and new advances, as well as the entrance and application of the subject into tourism studies. Country/region entries, each accompanied with a map, first describe the location, size, population, and economy. Main tourism appeals, products, source markets, arrivals and receipts, policy and organization, as well as education and training infrastructure, along with a prospective view of tourism development are common among these entries.

Issue-based entries address popular or known emerging problems of general and public concern, such as climate change, quality of life, and safety and security in tourism research and practice. Such entries introduce and define the issue, reflect on the evolution of the subject and factors contributing to its importance to or popularity in tourism, and review main research-based studies which reveal deeper layers and their contributions to the understanding of tourism as a whole.

Instead of demonstrating how to use an analytic tool, method/methodology entries focus on the origin and definition in the native field(s), including entrance to and application in tourism studies. Readers are also introduced to the advances of a method employed in tourism studies through a review of 
research-based works or case studies which unfold hidden layers in scholarly tourism literature.

Likewise, product and sector entries begin with a definitional introduction and reflect on factors contributing to the popularity and possible evolution of a product or sector, through reviewing published research or case studies. These entries also name countries or regions in which a product or sector has driven deep roots, types of tourists interested in them, as well as related governmental/ nongovernmental organizations fostering their development.

Unlike the first version, in the current edition, organization/association and journal/publication/media categories represent a number of synthesized or consolidated entries such as academic tourism journals, travel trade journals, organizations and associations, destination marketing organizations, national tourism offices and administration, scholarship, and universities. The roles and functions of such organizations or media entities in the tourism industry and/or in fostering research and practice are reflected through review discussions based on published studies.

\section{Weaving a Web of Tourism Knowledge}

This encyclopedia is intended for use by students, instructional staff, and scholars in tourism education programs and research institutions worldwide. Policymakers, consultants, and practitioners including destination marketers, managers, tourism developers and planners, attraction architects, and product designers can also benefit from the comprehensive coverage of alphabetic topics and subjects covered in this source. Indeed, like any other reference work, the reading of this encyclopedia defies convention or sequence. Readers are encouraged to follow their own interests and inclinations in exploring subjects covered in this volume, and to fully make use of its cross-references in order to weave "a web of tourism knowledge" of their own.

The encyclopedia is meant to inform, inspire, and prompt its readers to ask challenging questions in order to become more critical of, committed to, and/or involved in tourism research and scholarship. The usefulness of this edition of the Encyclopedia of Tourism will have to be left to maturation in time and to feedback from its readers. Fortunately, in this electronic age, shortcomings and updates reported to the chief editors will be periodically uploaded into the electronic publication. In such a manner, the completeness and currency of the encyclopedia reside in the hands of its readers, authors, scholars, and tourism knowledge trackers.

Jafar Jafari

University of Wisconsin-Stout, Menomonie, USA

Honggen Xiao

The Hong Kong Polytechnic University, Hong Kong, China

Co-Editor 



\section{Acknowledgments}

Acknowledging the cumulative efforts of an army of individuals who have made the publication of this important reference source possible is truly challenging. Its journey - guided by a multitude of editors and supported by the publishing house Springer - took 4 years of roadmapping to bring together 700 entry contributions by 766 authors from 113 countries. Like any other odyssey, this one had its peculiar ups and downs along the way, but what mattered most to everyone concerned was the successful landing of the Encyclopedia of Tourism. A debt of gratitude is extended to all the creators, shapers, and promoters of tourism knowledge jointly participating in the ensuing publication. Among this dedicated army, the authors are named individually after their entries, with the associate and resource editors listed after the title page. Associate editors in particular guided and influenced the development of each and every encyclopedia entry, from its initial submission to its eventual acceptance - often after several revisions and rewrites. Springer editors Tresa Benjamin, Samhita Das, Michael Hermann, Ashwani Veejai Raj, Christian Rauscher, Tina Shelton, Meghna Singh, and Jayanthi Vetriselvam are recognized for their work and commitment to this community knowledge project.

Special acknowledgments are extended to the affiliated institutions of the chief editors: the School of Hospitality Leadership, University of WisconsinStout (USA), and the School of Hotel and Tourism Management, the Hong Kong Polytechnic University (China). The latter provided support, dedicated office space and resources, and assistantships (G-UB11, PolyU 5444-13H, and PolyU 5494-12H), in addition to accommodating the many requirements of the coeditor.

Colleagues, academic staff, and research students from the coeditors' home institutions, as well as Universitat de les Illes Balears (Spain) and Universidade do Algarve (Portugal), are recognized for their participation in the workshops and/or involvement in feeding into this project. Singular thanks are also due to Dimitrios Buhalis, Kaye Chon, Eduardo Fayos-Solà, Keith Hollinshead, Cathy Hsu, Brian King, Rob Law, Bob McKercher, Daniel Scott, Stephen Smith, Haiyan Song, and many other colleagues across the world for offering advice in the design, development, and contents of this encyclopedia; to Ralf Buckley, João Sarmento, Askar Mukashev Serikboluly, and Geoffrey Wall for developing model entries at the early stage of the journey; to Nevenka Čavlek for mobilizing author networks during the editorial processes; and to 
Kuan-Huei Lee, Eddy Kurobuza Tukamushaba, and Xiaotao Yang for volunteering their time as editorial assistants in the early stages of this project. Heartfelt gratitude is expressed to the coeditors' families who accommodated - during the times which were theirs - the seemingly unending work of the encyclopedia.

This reference work is dedicated to the community of scholars engaged in investigating, conquering, populating, mapping, and landmarking this rapidly expanding multidisciplinary landscape of knowledge in tourism. They are the ultimate contributors and beneficiaries of this Encyclopedia of Tourism. 


\section{Editors}

Jafar Jafari

University of Wisconsin - Stout, Menomonie, USA

Honggen Xiao

The Hong Kong Polytechnic University, Hong Kong, China 



\section{Associate Editors}

\section{Graham M. S. Dann}

UiT Arctic University of Norway, Alta, Norway

Juergen Gnoth

University of Otago, Dunedin, New Zealand

\section{Tazim Jamal}

Texas A\&M University, College Station, USA

\section{Scott Meis}

Tourism HR Canada, Ottawa, Canada

\section{Ana María Munar}

Copenhagen Business School, Copenhagen, Denmark

\section{Melville Saayman}

North-West University, Potchefstroom, South Africa

\section{Regina Schlüter}

Universidad Nacional de Quilmes, Bernal, Buenos Aires, Argentina

\section{Noel Scott}

Griffith University - Gold Coast, Queensland, Australia

\section{Tej Vir Singh}

Tourism Recreation Research, Lucknow, India

\section{Resource Editors}

\section{René Baretje-Keller}

Centre International de Recherches et d'Etudes Touristiques, Aix en Provence, France

\section{Christopher Cheng}

The Hong Kong Polytechnic University, Hong Kong, China 



\section{Contributors}

Prince Sultan Bin Salman Bin Abdulaziz Saudi Commission for Tourism and Antiquities, Riyadh, Saudi Arabia

Wesal Abou-Alam Hotel Management, Helwan University, Cairo Governorate, Egypt

Nuno Abranja Tourism Department, Instituto Superior de Ciências Educativas - Odivelas, Portugal

Kathleen M. Adams Department of Anthropology, Loyola University Chicago, Chicago, IL, USA

James Brian Aday Hospitality and Tourism Management, San Francisco State University, College of Business, San Francisco, CA, USA

Edward Addo School of Business, Tourism and Hospitality Management, Zenith University College, Accra, Ghana

Galal M. H. Afifi College of Arts and Social Sciences, Sultan Qaboos University, Al-Khoudh, Muscat, Oman

Dora Agapito Faculty of Economics, University of Algarve, Faro, Portugal

Eugeni Aguiló-Pérez Department of Applied Economics, Universitat de les Illes Balears, Islas Baleares, Palma de Mallorca, Spain

Santana-Talavera Agustin Institute of Political and Social Sciences, University of La Laguna, San Cristobal de La Laguna, Spain

Rein Ahas Department of Geography, University of Tartu, Tartu, Estonia

Suzanne Ainley Research Analyst Program, Georgian College, Barrie, ON, Canada

David Airey School of Hospitality and Tourism Management, University of Surrey, Guildford, UK

Gürkan Akdăg Faculty of Tourism, Mersin University, Mersin, Turkey

Azwin Aksan Universiti Teknologi MARA, Selangor, Malaysia

Gurhan Aktas Dokuz Eylul University, Izmir, Turkey

Mohammad M. Alazaizeh Department of Travel and Tourism Management, The University of Jordan, Aqaba, Jordan 
Hamed Al-Azri Marketing Department, Sultan Qaboos University, Muscat, Oman

Antonio Alcover Casasnovas Departament d'Economia Aplicada, Universitat de les Illes Balears, Palma de Mallorca, Islas Baleares, Spain

Khaled Alduais Arab Tourism Experts Association, Sana'a, Yemen

Nazia Ali Institute for Tourism Research, University of Bedfordshire, Luton, Bedfordshire, UK

Thiago Allis Department of Geography, Tourism and Humanities, Universidade Federal de São Carlos, São Carlos, Brazil

Fernando Almeida-García School of Tourism, University of Malaga, Málaga, Spain

Areej Shabib Aloudat Yarmouk University, Irbid, Jordan

Nidal M. Alzboun Department of Travel and Tourism Management, The University of Jordan, Aqaba, Jordan

Carla A. F. Amado Faculty of Economics, University of Algarve, Faro, Portugal

Kathleen Andereck School of Community Resources and Development, Arizona State University, Phoenix, AZ, USA

Tommy D. Andersson Centre for Tourism, School of Business Economics and Law at Gothenburg University, Gothenburg, Sweden

Marta Gemma Nel-lo Andreu Geography Department, Universitat Rovira i Virgili, Tarragona, Spain

Hazel Andrews Faculty of Education, Health and Community, Liverpool John Moores University, Liverpool, UK

Jo Ankor Flinders University, Bedford Park, SA, Australia

John Ap Stenden University, Doha, Qatar

Masashi Arakawa Graduate School of Tourism Sciences, University of the Ryukyus, Okinawa, Japan

Julio Aramberri School of Tourism and Hospitality Management, Dongbei University of Finance and Economics, Dalian, Liaoning, China

John Armbrecht Centre for Tourism, School of Business Economics and Law at Gothenburg University, Gothenburg, Sweden

Fernanda César Arnaiz Universidad Anáhuac-Puebla, Puebla, Mexico

Stella Maris Arnaiz Burne Universidad de Guadalajara, Jalisco, Mexico

Guy Assaker School of Business, Lebanese American University, Beirut, Lebanon 
Norman Au School of Hotel and Tourism Management, The Hong Kong Polytechnic University, Hong Kong, China

Onome Awaritefe Department of Geography and Regional Planning, Delta State University, Abraka, Nigeria

Matylda Awedyk Department of Geography of Tourism and Landscape, E. Piasecki University School of Physical Education in Poznań, Poznań, Poland

Julian K. Ayeh Department of Hospitality and Tourism Management, University of Cape Coast, Cape Coast, Ghana

Kenneth F. Backman The Department of Parks, Recreation, and Tourism Management, Clemson University, Clemson, SC, USA

Rodolfo Baggio Economics and Tourism, Bocconi University, Milan, Italy

Josep A. Ivars Baidal Tourism Research Institute, Alicante University, Alicante, Spain

Vida Bajc Department of Sociology, Methodist University, Fayetteville, NC, USA

Martine Bakker Tisch Center for Hospitality, Tourism, and Sports Management, New York University, New York, NY, USA

Abdoulaye Garba Bako Institute of Social Sciences, Tourism Management Graduate Program, Mersin University, Mersin, Turkey

Magdalena Banaszkiewicz Jagiellonian University, Cracow, Poland

Yacouba Banhoro Department of History, Archaeology and History of Art, Université de Ouagadougou, Ouagadougou, Burkina Faso

Jigang Bao Center for Tourism Planning and Research, Sun Yat-sen University, Guangzhou, China

Esteban Bardolet Department of Applied Economics, Universitat de les Illes Balears, Palma de Mallorca, Spain

Lynn A. Barnett Department of Recreation, Sport and Tourism, University of Illinois at Urbana-Champaign, Champaign, IL, USA

Thierno Aliou Barry IGEAT, Université libre de Bruxelles, Brussels, Belgium

Thomas G. Bauer Dundee Park Academy, Mission Beach, QLD, Australia

Jannes Bayer Management Center Innsbruck, Innsbruck, Austria

Lionel Bécherel International Tourism Consultancy Associates, London, UK

Susanne Becken Griffith Institute for Tourism, Griffith Business School, Griffith University, Queensland, Australia

Fritz Becker Department of Geography and Environmental Studies, University of Namibia, Windhoek, Namibia 
Lisa Beesley Department of Tourism, Sport and Hotel Management, Griffith University, Nathan, QLD, Australia

Yaniv Belhassen Department of Hotel and Tourism Management, Eilat Campus, Ben-Gurion University of the Negev, Beer-Sheva, Israel

Felix Gasten Bello Department of Tourism, Mzuzu, Malawi

Pierre Benckendorff UQ Business School, The University of Queensland, Brisbane, QLD, Australia

Elizabeth Ifeyinwa Benson Obafemi Awolowo University, Ile-Ife, Nigeria

Liza Berdychevsky Department of Recreation, Sport and Tourism, College of Applied Health Sciences, University of Illinois at Urbana-Champaign, Champaign, IL, USA

Tracy Berno Faculty of Environment, Society and Design, Lincoln University, Christchurch, New Zealand

Mechelle Best Recreation and Tourism Management, California State University, Northridge, CA, USA

Salvatore Bimonte Department of Economics and Statistics, University of Siena, Siena, Italy

Geoffrey R. Bird School of Tourism and Hospitality Management, Royal Roads University, Victoria, BC, Canada

Rosemary Black School of Environmental Sciences, Charles Sturt University, Albury, NSW, Australia

Adam Blake Faculty of Management, Bournemouth University, Poole, UK

Sue Bleasdale Department of Marketing, Branding and Tourism, Middlesex University, London, UK

Bodil Stilling Blichfeldt Department of Culture and Global Studies, Aalborg University, Aalborg, Denmark

A. Lynn Bolles Department of Anthropology, University of Maryland, College Park, MD, USA

Karla Boluk Department of Recreation and Leisure Studies, University of Waterloo, Waterloo, Ontario, Canada

Andreea Botoş The Bucharest University of Economic Studies, Bucuresti, Romania

Nourddine Bouanani KATLYSE, Blida, Algeria

Christine Boven International Management for Service Industries, BiTS Business and Information Technology School GmbH, Iserlohn, Germany

Bill Bramwell Centre for Tourism, Hospitality and Events Research, Sheffield Business School, Sheffield Hallam University, Sheffield, UK 
Caroline Bremner Travel and Tourism, Euromonitor International, London, UK

Patrick Brouder School of Tourism and Hospitality, University of Johannesburg, Johannesburg, South Africa

Desmond O. Brown Department of Retailing and Tourism Management, University of Kentucky, Lexington, KY, USA

Ralf Buckley International Chair in Ecotourism Research, Griffith University, Gold Coast, QLD, Australia

Karolina Buczkowska Poznan University School of Physical Education, Poznan, Poland

Dimitrios Buhalis School of Tourism, Bournemouth University, Poole, Dorset, UK

Robyn Bushell School of Social Science and Psychology, Western Sydney University, Penrith, Australia

Richard Butler Department of Management, University of Strathclyde, Glasgow, UK

Christine Buzinde School of Community Resources and Development, Arizona State University, Phoenix, AZ, USA

Paulette Bynoe School of Earth and Environmental Sciences, University of Guyana, Georgetown, Guyana

Bernardi Cabrer Borras Department of Applied Economics, University of Valencia, Valencia, Spain

Liping A. Cai Purdue Tourism and Hospitality Research Center, Purdue University, West Lafayette, IN, USA

A. Celil Çakici Faculty of Tourism, Mersin University, Mersin, Turkey

Blanca A. Camargo International Tourism Program, Universidad de Monterrey, San Pedro Garza García, Mexico

Acolla Cameron Department of Management Studies, University of the West Indies, St Augustine, Trinidad and Tobago

Phil Cameron King AbdulAziz University, Tourism Institute, Jeddah, Kingdom of Saudi Arabia

Kom Campiranon DPU International College, Dhurakij Pundit University, Bangkok, Thailand

Rossana Campodónico Área de Estudios Turísticos - FHCE, Universidad de la República, Montevideo, Uruguay

Luís Manuel Tomás Galiza Cardoso University of Aveiro, Aveiro, Portugal Jack Carlsen Curtin Business School, Curtin University, Bentley, WA, Australia 
Barbara Carmichael Faculty of Arts, Department of Geography and Environmental Studies, Wilfrid Laurier University, Waterloo, ON, Canada

Daniel Carmona-Zubiri Ciencias Sociales y Humanas, University Miguel Hernández de Elche, Elche, Spain

Elizabeth Carnegie University of Sheffield, Sheffield, UK

Neil Carr Department of Tourism, University of Otago, Dunedin, New Zealand

Sandra Carvao UNWTO, Madrid, Spain

Eugénia Castela Faculty of Economics, University of Algarve, Faro, Portugal

Guilherme Castela Faculty of Economics, University of Algarve, Faro, Portugal

James Guy Castley The Griffith School of Environment, Griffith University, Gold Coast, QLD, Australia

Kellee Caton Tourism Management Department, Thompson Rivers University, Kamloops, Canada

Senija Causevic Faculty of Law and Social Sciences, School of Oriental and African Studies, University of London, London, UK

Jenny Cave Department of Tourism Management, University of Waikato, Hamilton, New Zealand

Nevenka Čavlek Department of Tourism, Faculty of Economics and Business, University of Zagreb, Zagreb, Croatia

Mary Cawley School of Geography and Archaeology, National University of Ireland Galway, Galway, Ireland

Emilio Celotto International Centre of Studies on Tourism Economics, CISET - Ca' Foscari University, Oriago di Mira (Venice), Italy

Samia Chahine Government of Morocco, Rabat, Morocco

Donna Chambers Tourism, Hospitality and Events, University of Sunderland, Sunderland, UK

Eric S. W. Chan School of Hotel and Tourism Management, The Hong Kong Polytechnic University, Hong Kong, China

Wilco Chan School of Hotel and Tourism Management, The Hong Kong Polytechnic University, Hong Kong, China

Samantha Chaperon Business School, University of Greenwich, Greenwich, London, UK

Joseph M. Cheer Faculty of Arts, Monash University, Clayton, VIC, Australia 
Ganghua Chen School of Tourism Management, Sun Yat-sen University, Guangzhou, China

Po-Ju Chen Rosen College of Hospitality Management, University of Central Florida, Orlando, FL, USA

Xu Chen Baidu Marketing Institute, Beijing, China

Catherine Cheung School of Hotel and Tourism Management, The Hong Kong Polytechnic University, Hong Kong, China

Deepak Chhabra School of Community Resources and Development, Arizona State University, Phoenix, AZ, USA

Rahim Heydari Chianeh Department of Geography and Urban Planning, Faculty of Geographer and Planning, University of Tabriz, Tabriz, East Azarbayjan, Iran

Li-Ming Chiang Department of Hotel, Restaurant and Toursim Management, College of Business and Management, East Stroudsburg University, East Stroudsburg, PA, USA

Garry Chick Pennsylvania State University, Pennsylvania, USA

Jaeyeon Choe Bournemouth University, Poole, UK

Hwansuk Chris Choi School of Hospitality, Food and Tourism Management, University of Guelph, Guelph, ON, Canada

Kaye Chon School of Hotel and Tourism Management, The Hong Kong Polytechnic University, Hong Kong, China

Hyungsuk Choo Tourism, Leisure, and Event Planning, School of Human Movement, Sports, and Leisure Studies, Bowling Green, OH, USA

Athinodoros Chronis California State University, Stanislaus, Turlock, CA, USA

Alan Clarke Faculty of Economics, University of Pannonia, Veszprém, Hungary

Paul Cleave Business School, University of Exeter, Exeter, UK

Isabelle Cloquet IGEAT - Faculty of Science, Université Libre de Bruxelles, Brussels, Belgium

Roberto Codas Desarrollo Empresarial, Asunción, Paraguay

Alexandra Coghlan Centre for Tourism, Sport and Services Research, Griffith University, Gold Coast, QLD, Australia

Erik Cohen Department of Sociology and Anthropology, The Hebrew University of Jerusalem, Jerusalem, Israel

Scott A. Cohen School of Hospitality and Tourism Management, University of Surrey, Guildford, UK

Tim Coles University of Exeter Business School, Exeter, UK 
Noga Collins-Kreiner Department of Geography and Environmental Studies, University of Haifa, Haifa, Israel

Fredrick M. Collison School of Travel Industry Management, University of Hawaii at Manoa, Honolulu, HI, USA

Chris Cooper Business Faculty, Oxford Brookes University, Oxford, UK

Malcolm Cooper Graduate School of Asia Pacific Studies, Ritsumeikan Asia Pacific University, Beppu, Oita Prefecture, Japan

Antonia Correia Faculty of Economics, CEFAGE, University of Algarve, Faro, Portugal

Rafael Cortés-Macías Faculty of Tourism, University of Malaga, Malaga, Spain

Glen Olivier Cousquer Institute of Geography, University of Edinburgh, Edinburgh, Scotland, UK

Geoffrey I. Crouch La Trobe Law School, Faculty of Business, Economics and Law, La Trobe University, Melbourne, VIC, Australia

Glen Croy Department of Management, Monash University, Caulfield East, VIC, Australia

Judith Cukier Geography and Environmental Management, University of Waterloo, Waterloo, ON, Canada

Milan Culic Centre for Tourism Research and Studies, Novi Sad, Serbia

Catherine Culver Department of Tourism, Recreation and Sport Management, College of Health and Human Performance, University of Florida, Gainesville, FL, USA

Julio da Costa Mendes Faculty of Economics, University of Algarve, Faro, Portugal

Helena Cláudia da Cruz Albuquerque Department of Environment and Planning, University of Aveiro, Aveiro, Portugal

João Albino Matos da Silva Faculty of Economics, University of Algarve, Faro, Portugal

Heidi Dahles Department of International Business and Asian Studies, Griffith University, Nathan, QLD, Australia

Graham M. S. Dann UiT Arctic University of Norway, Alta, Norway

Pheroza Daruwalla School of Business, University of Western Sydney, Richmond, NSW, Australia

Stefano De Cantis Department of Economics, Business and Statistics, University of Palermo, Palermo, Italy

Suzanne de la Barre Department of Recreation and Tourism Management, Vancouver Island University, Nanaimo, BC, Canada 
Javier de León Institute of Tourism and Sustainable Economic Development, Universidad de Las Palmas de Gran Canaria, Las Palmas de Gran Canaria, Spain

Liza Debevec International Water Management Institute, Addis Ababa, Ethiopia

Patrick L'Espoir Decosta Faculty of Business, Government and Law, University of Canberra, Canberra, Australia

Alain Decrop Department of Business Administration, University of Namur, Namur, Belgium

Giacomo Del Chiappa Department of Economics and Business, University of Sassari and CRENoS, Sassari, Italy

Anne-Marie d'Hauteserre School of Social Sciences, University of Waikato, Hamilton, New Zealand

Michael A. Di Giovine Department of Anthropology and Sociology, West Chester University of Pennsylvania, West Chester, USA

Gonzalo Díaz-Meneses Faculty of Economy, Business and Tourism, University of Las Palmas de Gran Canaria, The Canary Islands, Spain

Amy Diedrich College of Marine and Environmental Sciences, James Cook University, Townsville, Australia

Peter U. C. Dieke University of Nigeria, Nsukka, Nigeria

Anya Diekmann IGEAT, Université libre de Bruxelles, Brussels, Belgium

M. R. Dileep Pazhassiraja College, Calicut University, Kerala, India

Peiyi Ding Tourism Confucius Institute, Gold Coast Campus, Griffith University, Southport, Australia

Mihail-Cristian Diţoiu The Bucharest University of Economic Studies, Bucharest, Romania

Bongani Dlamini Swaziland Tourism Authority, Mbabane, Swaziland

Patrícia Oom do Valle Faculty of Economics, University of Algarve, Faro, Portugal

Sara Dolnicar UQ Business School, The University of Queensland, Brisbane, Australia

Josefina Domínguez-Mujica Human Geography, University of Las Palmas de Gran Canaria, Las Palmas, de Gran Canaria, Spain

Erwei Dong University of South Alabama, Alabama, USA

Holly Donohoe Department of Tourism, Recreation and Sport Management, College of Health and Human Performance, University of Florida, Gainesville, FL, USA 
Amartuvshin Dorjsuren Department of Tourism, National University of Mongolia, Ulaanbaatar, Mongolia

Megumi Doshita School of Global Studies, Tama University, Fujisawa, Japan

Ross Dowling School of Business and Law, Edith Cowan University, Joondalup, Australia

Ivo Druzic Faculty of Economics and Business, University of Zagreb, Zagreb, Croatia

Lauren Duffy Department of Parks, Recreation, and Tourism Management, Clemson University, Clemson, USA

Tara Duncan Otago Business School, University of Otago, Dunedin, New Zealand

Angela Durko Department of Recreation, Park, and Tourism Sciences, Texas A\&M University, College Station, USA

Larry Dwyer Faculty of Economics, University of Ljubljana, Ljubljana, Slovenia

Paul F. J. Eagles Department of Recreation and Leisure Studies, University of Waterloo, Waterloo, ON, Canada

Jonathan Edwards International Centre for Tourism and Hospitality Research, Bournemouth University, Poole, UK

Eke Eijgelaar Centre for Sustainable Tourism and Transport, NHTV Breda University of Applied Sciences, Breda, The Netherlands

Islam Elgammal Department of Tourism Studies, Faculty of Tourism, Suez Canal University, Ismailia, Egypt

Statia Elliot School of Hospitality, Food and Tourism Management, University of Guelph, Guelph, Canada

Jas' Elsner Corpus Christi College, Oxford University, Oxford, UK

Cathy A. Enz School of Hotel Administration, Cornell University, Ithaca, USA

Ron Erdmann Office of Travel and Tourism Industries, US Department of Commerce, Washington DC, USA

Patricia Erfurt-Cooper James Cook University, Cairns, Australia

Mingotto Erica CISET, Ca' Foscari University, Venice, Italy

Daniel L. Erkkila College of Food, Agricultural and Natural Resource Sciences, University of Minnesota, Grand Rapids, USA

Juan L. Eugenio-Martin Departamento de Análisis Económico Aplicado, Universidad de Las Palmas de Gran Canaria, Las Palmas, Spain 
Lochin Faizulloev Committee of Youth Affairs, Sports and Tourism, Government of Tajikistan, Dushanbe, Tajikistan

Sebastian Falck Tajik Association of Tourism Organisations, Dushanbe, Tajikistan

Lars Falk Hospitality and Experience Management, University College of Northern Denmark, Aalborg, Denmark

Hadil Munther Faris School of Hospitality Management and Tourism, Dublin Institute of Technology, Dublin, Ireland

Eduardo Fayos-Solà UNWTO, Ulysses Foundation, Madrid, Spain

William G. Feighery The Research Methods Laboratory, Neuchatel, Switzerland

David Fennell Department of Tourism and Environment, Brock University, St. Catharines, Canada

Alba Fernández Alonso Group TIDE - Tourism as an Instrument for Development, Luanda, Angola

Heredina Fernadez-Betancort Escuela Universitaria de Turismo of Lanzarote, University of Las Palmas de Gran Canaria, Tahíche, Lanzarote, Spain

Antonio Fernández-Morales Departamento de Economía Aplicada, Facultad de Ciencias Económicas y Empresariales, Universidad de Málaga, Malaga, Spain

Mauro Ferrante Facoltà di Economia, Department of Culture and Society, University of Palermo, Palermo, Italy

Paolo Figini Department of Economics, University of Bologna, Bologna, Italy

David Fisher Faculty of Environment, Society and Design, Lincoln University, Canterbury, New Zealand

John Fletcher Office of the Vice Chancellor, Bournemouth University, Fern Barrow, Poole, UK

Adao Flores University of Algarve, Faro, Portugal

Carmen Florido Department of Applied Economic Analysis, Universidad de Las Palmas de Gran Canaria, Las Palmas, Spain

Ali Hassan Follad Ministry of Industry, Commerce and Tourism, Manama, Bahrain

Raúl Peralba Fortuny Positioning Systems, Boadilla del Monte, Madrid, Spain

Anestis K. Fotiadis Department of Entertainment Management, I-Shou University, Kaohsiung, Taiwan 
Bohumil Frantál Department of Environmental Geography, Institute of Geonics, Czech Academy of Sciences, Brno, Czech Republic

Douglas C. Frechtling International Institute of Tourism Studies, The George Washington University, Washington DC, USA

Cristi Frent Icelandic Tourism Research Centre, Reykjavik, Iceland

Walter Freyer Technical University Dresden, Dresden, Germany

Alan Fyall University of Central Florida, Orlando, USA

Amareswar Galla International Institute for the Inclusive Museum, New Delhi, India

Martina G. Gallarza Department of Marketing, Universitat de Valéncia, Valencia, Spain

William C. Gartner Department of Applied Economics, University of Minnesota, Saint Paul, Minnesota, USA

Tometi Koku Gbedema Geography Graduate Group, University of California, Davis, USA

Babu P. George Department of Management, College of Business and Entrepreneurship, Fort Hays State University, Hays, KS, USA

Don Getz Calgary, Alberta, Canada

Chris Gibson Australian Centre for Cultural Environmental Research, University of Wollongong, Wollongong, Australia

Heather J. Gibson Department of Tourism, Recreation and Sport Management, University of Florida, Gainesville, USA

Rachel F. Giraudo Department of Anthropology, California State University, Northridge, USA

George Gmelch Anthropology Department, Union College, Schenectady, USA

José Manoel Gonçalves Gândara Universidad Federal de Parana, Curitiba, Brazil

Juergen Gnoth Department of Marketing, University of Otago, Dunedin, New Zealand

Nalaka Godahewa Securities and Exchange Commission of Sri Lanka and Sri Lanka Tourism, Colombo, Sri Lanka

Shaney Peña Gomez Centro de Innovación Atabey, Santo Domingo, Dominican Republic

Anton Gosar University of Primorska, Koper - Capodistria, Slovenia/European Union

Sashko Gramatnikovski University of Tourism and Management Skopje, Skopje, Macedonia 
David Green Department of Geography, King's College London, Strand, London, UK

Ulrike Gretzel UQ Business School, The University of Queensland, Brisbane, Australia

Kevin Griffin School of Hospitality Management and Tourism, Dublin Institute of Technology, Dublin, Ireland

Michael J. Gross School of Management, University of South Australia, Adelaide, Australia

Grace Guaigu University of Papua New Guinea, Port Moresby, Papua New Guinea

Manuela Guerreiro Faculty of Economics, University of Algarve, Faro, Portugal

Carla Guerrón Montero Department of Anthropology, University of Delaware, Newark, USA

Antonio Guevara Dpto. Lenguajes y Ciencias de la Computación, University of Malaga, Málaga, Spain

Basak Denizci Guillet School of Hotel and Tourism Management, The Hong Kong Polytechnic University, Hong Kong, China

Ozan Güler Faculty of Tourism, Mersin University, Mersin, Turkey

Dogan Gursoy School of Hospitality Business Management, Washington State University, Pullman, USA

Daniel A. Guttentag Department of Recreation and Leisure Studies, University of Waterloo, Waterloo, ON, Canada

Augustus W. Hallmon University of Illinois at Urbana-Champaign, Champaign, ON, USA

Sunny Ham Yonsei University, Seoul, South Korea

Kevin Hannam International Centre for Research into Events, Tourism and Hospitality, Leeds Beckett University, Leeds, UK

Xiaofei Hao Sun Yat-Sen University, Guangzhou, China

Tadayuki Hara Rosen College of Hospitality Management, University of Central Florida, Orlando, USA

David Harrison Middlesex University, London, UK

Toshiya Hashimoto College of Tourism, Rikkyo University, Niiza-shi, Saitama, Japan

Bente Haug Arctic University of Norway, Tromsø, Norway

Jan Vidar Haukeland Institute of Transport Economics, Oslo, Norway 
Don Hawkins School of Business, George Washington University, Washington, DC, USA

Iain Hay School of Environment, Flinders University, South Australia, Bedford Park, Australia

Carolyn E. Hayle Mona School of Business and Management, The University of the West Indies, Mona, Jamaica

Noel Healy Department of Geography, Salem State University, Salem, USA

Joan C. Henderson Nanyang Business School, Nanyang Technological University, Singapore

Inge Hermann Hospitality Business School, Saxion University of Applied Sciences, Deventer, The Netherlands

Alejandro Herrera Hispaniola Observatory for Sustainable Tourism, Santo Domingo, Dominican Republic

Freya Higgins-Desbiolles University of South Australia, Adelaide, Australia

Ralph Hissen-Lee Victoria, Seychelles

Martina Hoch Liechtenstein Marketing, Vaduz, Liechtenstein

Demian Hodari Ecole hôtelière de Lausanne, HES-SO University of Applied Sciences Western Switzerland, Lausanne, Switzerland

Patrick J. Holladay School of Hospitality, Sport and Tourism Management, Troy University, Brunswick, USA

Keith Hollinshead Department of Tourism Studies, University of Bedfordshire, Luton, Bedfordshire, UK

Glen Hornby University of New South Wales, Sydney, Australia

Graziela Scalise Horodyski Department of Tourism, Universidade Estadual de Ponta Grossa, Ponta Grossa, Brazil

Petri Hottola FUNTS, University of Eastern Finland, Savonlinna, Finland

Cathy H. C. Hsu School of Hotel and Tourism Management, The Hong Kong Polytechnic University, Hong Kong, China

Tzung-Cheng (T. C.) Huan College of Management, National Chiayi University, Chiayi, Taiwan

Songshan (Sam) Huang School of Management, University of South Australia, Adelaide, Australia

Wei-Jue Huang School of Hotel and Tourism Management, The Hong Kong Polytechnic University, Hong Kong, China

Zhuowei Huang Department of Recreation, Sport and Tourism, University of Illinois at Urbana-Champaign, Champaign, USA

Assumpció Huertas Rovira i Virgili University, Tarragona, Spain 
John Hull Faculty of Adventure, Culinary Arts and Tourism, Thompson Rivers University, Kamloops, BC, Canada

Kam Hung School of Hotel and Tourism Management, The Hong Kong Polytechnic University, Hong Kong, China

Carter A. Hunt Department of Recreation, Park, and Tourism Management, The Pennsylvania State University, Pennsylvania, USA

Sonja Hunter Samoa Tourism Authority, Apia, Samoa

William Cannon Hunter Department of Convention Management, Kyung Hee University, Seoul, South Korea

Alejandro Reyes Hurtado Education, Procibaris, Lima, Peru

Kenneth F. Hyde Faculty of Business and Law, Auckland University of Technology, Auckland, New Zealand

Svitlana Iarmolenko Georgia Southern University, Statesboro, USA

Federico Inchausti-Sintes Departamento de Análisis Económico Aplicado, Universidad de Las Palmas de Gran Canaria, Las Palmas, Spain

Rami K. Isaac Academy for Tourism, NHTV Breda University of Applied Sciences, Breda, The Netherlands

Milka Ivanova Institute for Tourism Research, University of Bedfordshire, Luton, UK

Stanislav Ivanov Varna University of Management, Varna, Bulgaria

Marta Jacob Department of Applied Economics, Universitat de les Illes Balears, Palma de Mallorca, Spain

Jens Kr. Steen Jacobsen Norwegian School of Hotel Management, University of Stavanger, Stavanger, Norway

Jafar Jafarov Azerbaijan Tourism and Management University, Baku, Azerbaijan

Beka Jakeli UNWTO, Madrid, Spain

Tazim Jamal Department of Recreation, Park and Tourism Sciences, Texas A\&M University, College Station, Texas, USA

SooCheong Shawn Jang Hospitality and Tourism Management, Purdue University, West Lafayette, USA

Hania Janta School of Hospitality and Tourism Management, University of Surrey, Guildford, UK

Philippe Jean-Pierre Centre d'Economie et Management de l'Ocean Indien, St-Denis, Réunion, France

Camilla Jensen Institute for Marketing and Management, University of Southern Denmark, Odense M, Denmark 
Martin Trandberg Jensen Department of Culture and Global Studies, Aalborg University, Copenhagen, Denmark

Hongyan Jia Department of Tourism, School of Humanity, Southeast University, Nanjing, China

Shan Jiang Capital Normal University, Beijing, China

Celeste Nava Jiménez Faculty of Tourism and Gastronomy, University Autonomous of State of Mexico, Toluca, Mexico

Xu Jing UNWTO, Madrid, Spain

WooMi Jo School of Hospitality, Food and Tourism Management, University of Guelph, Guelph, Canada

Nicholas E. Johnston Texas Tech University, Lubbock, USA

Lee Jolliffe Faculty of Business, University of New Brunswick, Saint John, NB, Canada

Adam Jones School of Sport and Service Management, University of Brighton, Brighton, UK

Andrew Jones Institute for Tourism, Travel and Culture, University of Malta, Msida, Malta

Calvin Jones Cardiff Business School, Cardiff University, Cardiff, UK

Darryl Jones Environmental Futures Research Institute, Griffith University, Nathan, QLD, Australia

Sam Jones Department of Economics, University of Copenhagen, Copenhagen, Denmark

Evan J. Jordan School of Travel Industry Management, University of Hawai'i at Manoa, Honolulu, USA

Cristina Jönsson Department of Management Studies, The University of the West Indies, Cave Hill, Barbados

Catalina Juaneda Department of Applied Economics, University of the Balearic Islands, Palma de Mallorca, Spain

Michel Julian UNWTO, Madrid, Spain

Anders Justenlund Hospitality and Experience Management, University College of Northern Denmark, Aalborg, Denmark

Nkongolo Kalala Bluegrass Community and Technical College, Lexington, KY, USA

Mark Kanning Lebanese American University, Beirut, Lebanon

Kemal Kantarci Department of Tourism Management, Alanya Faculty of Business, Akdeniz University, Kestel Campus, Alanya, Antalya, Turkey

Unnur B. Karlsdóttir East Iceland Heritage Museum, Egilsstaðir, Iceland 
Azadeh Kazeminia Azad University of Najafabad, Najafabad, Iran

Peter F. Keller Faculty of Business and Economics, University of Lausanne, Lausanne, Switzerland

Ian Kelly International Institute for Peace through Tourism (Australia) Inc., Golden Grove, Adelaide, South Australia

James Kennell University of Greenwich, Greenwich, UK

Christine L. Kern Tourism Faculty, University of Applied Sciences HTW Chur, Chur, Switzerland

John Kester UNWTO, Madrid, Spain

Jameel Khadaroo Department of Economics and Statistics, University of Mauritius, Reduit, Mauritius

Razan El Khatib Stenden University Qatar, Doha, Qatar

Catheryn Khoo-Lattimore Department of Tourism, Sport and Hotel Management, Griffith University, Nathan, Australia

Seongseop Kim School of Hotel and Tourism Management, The Hong Kong Polytechnic University, Hong Kong, China

Taehee Kim Hospitality and Tourism Management, Kyunghee University, Dongdaemun-gu, Seoul, South Korea

Yong Hee Kim School of Hotel and Tourism Management, The Hong Kong Polytechnic University, Hong Kong, China

Albert N. Kimbu School of Hospitality and Tourism Management, University of Surrey, Guildford, UK

Brian E. M. King School of Hotel and Tourism Management, The Hong Kong Polytechnic University, Hong Kong, China

Ksenia A. Kirillova School of Hotel and Tourism Management, The Hong Kong Polytechnic University, Hong Kong, China

Georg Klute Bayreuth International Graduate School of African Studies, University of Bayreuth, Bayreuth, Germany

Daniel C. Knudsen Department of Geography, Indiana University, Bloomington, USA

Maximiliano E. Korstanje Department of Economics, University of Palermo, Buenos Aires, Argentina

Auvo Kostiainen Department of European and World History, University of Turku, Turku, Finland

Dimitris Koutoulas Business Administration Department, University of Patras, Rio Patron, Greece

Metin Kozak School of Tourism and Hospitality Management, Dokuz Eylul University, Foça-İZMİR, Turkey 
John Kracht Rosen College of Hospitality Management, University of Central Florida, Orlando, USA

Damir Krešić Institute for Tourism, Zagreb, Croatia

Deniz Kucukusta School of Hotel and Tourism Management, The Hong Kong Polytechnic University, Hong Kong, China

Francis Kwansa University of Delaware, Newark, USA

Rick Lagiewski Department of Hospitality and Tourism Management, Rochester Institute of Technology, Rochester, USA

Christa Laing Department of Management Studies, University of the West Indies, St Augustine, Trinidad and Tobago

Svein Larsen Department of Psychosocial Science, University of Bergen, Bergen, Norway

Raymond W. K. Lau School of Arts and Social Sciences, The Open University of Hong Kong, Hong Kong, China

Jakob Lauring Department of Management, University of Aarhus, Aarhus, Denmark

Rob Law School of Hotel and Tourism Management, The Hong Kong Polytechnic University, Hong Kong, China

Rebecca A. Leadbeater Hilton Worldwide, Orlando, FL, USA

Sonja Sibila Lebe Faculty of Economics and Business, University of Maribor, Maribor, Slovenia

Bob Lee College of Education and Human Development, Bowling Green State University, Bowling Green, USA

Christine Lee Federation Business School, Federation University, Churchill, VIC, Australia

Gyehee Lee Kyung Hee University, Seoul, South Korea

Jinsoo Lee School of Hotel and Tourism Management, The Hong Kong Polytechnic University, Hong Kong, China

Kuan-Huei Lee Singapore Institute of Technology, Singapore

Louisa Yee-Sum Lee School of Business, James Cook University, Townsville, Australia

Woojin Lee School of Community Resources and Development, Arizona State University, Phoenix, AZ, USA

Xinran Y. Lehto School of Hospitality and Tourism Management, Purdue University, West Lafayette, USA

Naomi Leite SOAS, University of London, London, UK 
José Leiva Department of Computer Science, University of Málaga, Malaga, Spain

Raynald Harvey Lemelin School of Outdoor Recreation, Parks and Tourism, Lakehead University, Thunder Bay, Canada

Monkgogi Lenao University of Botswana, Gaborone, Botswana

Jaap Lengkeek Recreation and Tourism, Wageningen University, Wageningen, The Netherlands

Carmelo J. León Institute of Tourism and Sustainable Economic Development, Universidad de Las Palmas de Gran Canaria, Las Palmas de Gran Canaria, Spain

Daniel Leung Department of Tourism and Service Management, MODUL University Vienna, Vienna, Austria

Gang Li School of Hospitality and Tourism Management, University of Surrey, Guildford, UK

Mimi Li School of Hotel and Tourism Management, The Hong Kong Polytechnic University, Hong Kong, China

Xiang (Robert) Li School of Tourism and Hospitality Management, Temple University, Philadelphia, USA

Xiangping Li Institute for Tourism Studies, Macao, China

Daniela Liggett University of Canterbury, Christchurch, New Zealand

Vera Shanshan Lin Zhejiang University, Hangzhou, China

Zhaoping (George) Liu School of Hotel and Tourism Management, The Hong Kong Polytechnic University, Hong Kong, China

Claire Liu School of Hospitality and Tourism, Faculty of Culture and Society, Auckland University of Technology, Auckland, New Zealand

Darius Liutikas Lithuanian Social Research Centre, Vilnius, Lithuania

Ada Lo School of Hotel and Tourism Management, The Hong Kong Polytechnic University, Hong Kong, China

Brent Lovelock Department of Tourism, University of Otago, Dunedin, New Zealand

Tiffany Low School of Management and Business, Aberystwyth University, Aberystwyth, Ceredigion, UK

Zhen Lu Ted Rogers School of Hospitality and Tourism Management, Ryerson University, Toronto, ON, Canada

Joana Lucas Faculty of Social Sciences and Humanities, Universidade Nova de Lisboa, Lisbon, Portugal

Michael Lueck School of Hospitality and Tourism, Auckland University of Technology, Auckland, New Zealand 
Peter Lugosi Oxford School of Hospitality Management, Oxford Brookes University, Oxford, UK

Jian Ming Luo Faculty of International Tourism and Management, City University of Macao, Macao, China

Emily Ma Griffith Business School, Griffith University, Brisbane, Australia Elizabeth Mackay Centre for Hotel and Tourism Management, The University of The West Indies, Nassau, Bahamas

Kelly J. MacKay Ted Rogers School of Hospitality and Tourism Management, Ryerson University, Toronto, Canada

Francisco Madrid School of Tourism, Anáhuac University, Huixquilucan, Mexico

Patrick T. Maher Department of Community Studies, Cape Breton University, Sydney, Canada

Garret Maher Humanities and Social Sciences Department, Gulf University for Science and Technology, Mubarak Al-Abdullah, Kuwait

Heather Mair Department of Recreation and Leisure Studies, University of Waterloo, Waterloo, ON, Canada

Justyna Majewska Department of International Economics, Poznań University of Economics and Business, Poznań, Poland

Athena H. N. Mak Department of Tourism, Recreation and Leisure Studies, National Dong Hwa University, Shoufeng, Hualien, Taiwan

Carles Manera Department of Applied Economics, University of the Balearic Islands, Palma de Mallorca, Spain

Ajay Manrai Orchard Road and Amstel Avenue, Newark, USA

Lalita Manrai Orchard Road and Amstel Avenue, Newark, USA

Yoel Mansfeld Geography and Environmental Studies, Center for Tourism Research, University of Haifa, Haifa, Israel

David Manuel-Navarrete School of Sustainability, Arizona State University, Tempe, USA

Artak Manukyan Armenian State University of Economics, Yerevan, Armenia

Haretsebe Manwa North West University, Mahikeng, South Africa

Manente Mara CISET, Ca' Foscari University, Venice, Italy

Lawal Marafa Department of Geography and Resource Management, Chinese University of Hong Kong, Hong Kong, China

Kevin Markwell School of Business and Tourism, Southern Cross University, East Lismore, Australia 
Cipriano Marín Instituto de Astrofísica de Canarias, StarLight Initiative, Tenerife, Spain

João Filipe Marques Faculty of Economics, University of Algarve, Faro, Portugal

Keir Martin Department of Social Anthropology, University of Oslo, Oslo, Norway

Filomena Maria Cardoso Pedrosa Martins Department of Environment and Planning, University of Aveiro, Aveiro, Portugal

Giuseppe Marzano Universidad de Las Américas, Quito, Ecuador

Azizan Marzuki School of Housing Building and Planning, Universiti Sains Malaysia, Georgetown, Pulau Pinang, Malaysia

Lorenzo Masiero School of Hotel and Tourism Management, The Hong Kong Polytechnic University, Hong Kong, China

Antonio Massieu UNWTO, Madrid, Spain

Lidia Svendsen Maza Dept. de Economia y Administracion de Empresas, Universidad de Málaga, Malaga, Spain

Josef A. Mazanec Department of Tourism and Service Management, MODUL University Vienna, Vienna, Austria

Mohammad Nurul Huda Mazumder Faculty of Administrative Sciences, Laval University, Quebec, Canada

Marica Mazurek Matej Bel University, Banska Bystrica, Slovakia

Scott McCabe Nottingham University Business School, University of Nottingham, Nottingham, UK

Nancy McGehee Hospitality and Tourism Management, Virginia Polytechnic and State University, Blacksburg, VA, USA

Robyn McGuiggan Division of Global Strategy and Engagement, James Cook University, Cairns, Australia

Erin McKenna Department of Recreation, Sport and Tourism, University of Illinois at Urbana-Champaign, Champaign, IL, USA

Bob McKercher School of Hotel and Tourism Management, The Hong Kong Polytechnic University, Hong Kong, China

Karen McNamara School of Geography, Planning and Environmental Management, University of Queensland, Brisbane, Australia

Barbara J. McNicol Department of Earth and Environmental Sciences, Mount Royal University, Calgary, Canada

Sean Meadows Faculty of Liberal Arts, Siam University, Phasi Charoen, Thailand 
Beata Medynska-Gulij Department of Cartography and Geomatics, Institute of Physical Geography and Environmental Planning, Adam Mickiewicz University, Poznań, Poland

Scott Meis Tourism HR Canada, Ottawa, Canada

Moustafa A. Mekawy Tourism Studies Department, Faculty of Tourism and Hotels, Sadat City University, Sadat City, Egypt

Miguela M. Mena University of the Philippines, Asian Institute of Tourism, Quezon City, Philippines

Alfredo Mena-Navarro Faculty of Tourism, University of Malaga, Malaga, Spain

Fang Meng School of Hotel, Restaurant and Tourism Management, University of South Carolina, Columbia, SC, USA

Salvatore Messina Fondacioni Europa, Tirana, Albania

Josefa García Mestanza Departamento de Economía y Administración de Empresas, Universidad de Málaga, Málaga, Spain

Michelle Metro-Roland Department of Geography, Western Michigan University, Kalamazoo, USA

Christine Metusela Centre for Health Research, Western Sydney University, Campbelltown, Australia

John T. Mgonja Clemson University, Clemson, USA

Tanja Mihalič Faculty of Economics, University of Ljubljana, Ljubljana, Slovenia

Marie Vestergaard Mikkelsen Department of Culture and Global Studies, Aalborg University, Aalborg, Denmark

Ace Milenkovski University of Tourism and Management Skopje, Skopje, Macedonia

Valeria Minghetti International Centre of Studies on Tourism Economics, CISET - Ca' Foscari University, Oriago di Mira (Venice), Italy

Lynn Minnaert Preston Robert Tisch Center for Hospitality and Tourism, New York University, New York, USA

Božena Krce Miočić Department of Tourism and Communication Studies, University of Zadar, Zadar, Croatia

Sada Mire Leiden University, Leiden, The Netherlands

Clare J. A. Mitchell Geography and Environmental Management, University of Waterloo, Waterloo, ON, Canada

Amir H. Moghaddam Hacettepe University, Ankara, Iran

Janet Momsen Department of Human Ecology, University of California, Davis, USA 
Chollada Mongkhonvanit Faculty of Liberal Arts, Siam University, Phasi Charoen, Thailand

Rosario Monter Department of Business Economics, Universitat des Illes Baleares, Palma de Mallorca, Spain

Kevin Moore Faculty of Environment, Society and Design, Lincoln University, Lincoln, Canterbury, New Zealand

Yeganeh Morakabati Faculty of Management, Bournemouth University, Fern Barrow, Poole, UK

Damian Morgan Federation Business School, Federation University, Churchill, Australia

Nigel Morgan School of Hospitality and Tourism Management, University of Surrey, Guildford, UK

Stephanie Morris The Emirates Academy of Hospitality Management, Dubai, UAE

Alastair M. Morrison College of Health and Human Sciences, Purdue University, West Lafayette, IN, USA

Lena Mortensen Department of Anthropology, University of Toronto, Toronto, Canada

Gianna Moscardo College of Business, Law and Governance, James Cook University, Townsville, Australia

Omar Moufakkir Gulf University for Science and Technology, Kuwait City, Kuwait

Olga Martinez Moure UDIMA Universidad a Distancia de Madrid, Collado Villalba, Madrid, Spain

Ahmad Muhammad Ragab Minia University, Minya, Egypt

Martina Müller Teesside University, Middlesbrough, UK

Ian E. Munanura Department of Forest Ecosystems and Society, Oregon State Univesity, Corvallis, Oregon, USA

Ana María Munar Department of International Economics and Management, Copenhagen Business School, Frederiksberg Palace, Denmark

Takaruza Munyanyiwa Pro Vice Chancellor's Office, University of Zimbabwe, Harare, Zimbabwe

Dan Musinguzi Stenden University Qatar, Doha, Qatar

Patrick Naef Department of Anthropology, University of California at Berkeley, Berkeley, USA

Dedinha Domingos Nancassa Department of Geography, Tourism and Humanities, Universidade Federal de São Carlos, São Carlos, Brazil 
Masood A. Naqvi Centre for Tourism Research and Development, Lucknow, India

Syed Masood Ansar Naqvi Centre for Tourism Research and Development, Lucknow, India

Nikola Naumov Department of Geography, King's College London, Strand, London, UK

Enrique Navarro-Jurado Department of Geography, Faculty of Tourism, University of Málaga, Malaga, Spain

Omar Nawaz UNWTO, Madrid, Spain

Samba Ndiaye Universidade do Minho, Braga, Portugal

Marcelino Castillo Nechar Faculty of Tourism and Gastronomy, University Autonomous of State of Mexico, Toluca, Mexico

Velvet Nelson Department of Geography and Geology, Sam Houston State University, Huntsville, USA

Sanjay Nepal Department of Geography and Environmental Management, University of Waterloo, Waterloo, ON, Canada

Alexandre Panosso Netto Universidade de São Paulo, São Paulo, Brazil

Bart Neuts Auckland University of Technology, Auckland, New Zealand

Trent Newmeyer Department of Recreation and Leisure Studies, Brock University, St. Catharines, Canada

Carmen Nibigira Department of Parks, Recreation and Tourism Management, Clemson University, Clemson, SC, USA

Juan L. Nicolau Faculty of Economics, University of Alicante, Alicante, Spain

Viachaslau Nikitsin University of Paderborn, Paderborn, Germany

Steve Noakes Department of Tourism, Leisure, Hotel and Sport Management, Griffith University, Queensland, Australia

Antonio Miguel Nogués-Pedregal Department of Social and Human Sciences, Universitas Miguel Hernández of Elche, Elche, Spain

Marina Novelli School of Sport and Service Management, University of Brighton, Eastbourne, UK

Chaim Noy Department of Communication, University of South Florida, Tampa, USA

Luyaku Loko Nsimpasi Fund for Agricultural Development, Rome, Italy

Robin Nunkoo Faculty of Law and Management, University of Mauritius, Reduit, Mauritius 
Gyan Nyaupane School of Community Resources and Development, Julie Ann Wrigley Global Institute of Sustainability, Arizona State University, Phoenix, AZ, USA

Lars Nyberg Department of Tourism Studies, Mid Sweden University, Östersund, Sweden

Robert M. O'Halloran College of Business, East Carolina University, Greenville, USA

Yasuo Ohe Department of Food and Resource Economics, Chiba University, Matsudo, Japan

Roselyne N. Okech Division of Social Science / Tourism Studies, Memorial University of Newfoundland, Corner Brook, NL, Canada

Fevzi Okumus Rosen College of Hospitality Management, University of Central Florida, Orlando, USA

Joseph T. O'Leary Human Dimensions of Natural Resources, Colorado State University, Fort Collins, USA

Antonino Mario Oliveri Department of Cultures and Society, Università degli Studi di Palermo, Palermo, Italy

Daniel H. Olsen Department of Geography, Brigham Young University, Provo, UT, USA

Oghenekaro Omodior Department of Tourism, Recreation and Sport Management, University of Florida, Gainesville, FL, USA

Tom G. Ondicho Institute of Anthropology, Gender and African Studies, University of Nairobi, Nairobi, Kenya

Chin-Ee Ong Cultural Geography Chair Group, Wageningen University, Wageningen, The Netherlands

Can-Seng Ooi Department of International Economics and Management, Copenhagen Business School, Frederiksberg, Denmark

Mark Orams School of Sport and Recreation, Auckland University of Technology, Auckland, New Zealand

Michael O'Regan Bournemouth University, Fern Barrow, Poole, UK

Nor'Ain Othman Faculty of Hotel and Tourism Management, Universiti Teknologi MARA, Puncak Alam, Selangor, Malaysia

Anja Pabel School of Business and Law, Central Queensland University, Cairns, Australia

Nicola J. Palmer Department of Service Sector Management, Sheffield Business School, Sheffield Hallam University, Sheffield, UK

Bing Pan School of Business, College of Charleston, Charleston, USA 
Steve Pan School of Hotel and Tourism Management, The Hong Kong Polytechnic University, Hong Kong, China

Andreas Papatheodorou London College of Hospitality and Tourism, University of West London, London, UK

Cody Morris Paris Department of Economics and International Development, Middlesex University, Dubai, UAE

Hyung Yu Park Business School, Middlesex University, London, UK

Sanghee Park School of Management and Labor Relations, Rutgers, State University of New Jersey, Piscataway, USA

Giuli Liebman Parrinello Università Roma Tre, Rome, Italy

Dália Paulo Municipal Museum of Loulé, Loulé, Portugal

Ivana Pavlić Department of Economics and Business Economics, University of Dubrovnik, Dubrovnik, Croatia

Margarita Payeras Department of Applied Economics, Universitat de les Illes Balears, Palma de Mallorca, Spain

Douglas G. Pearce School of Management, Victoria University of Wellington, Wellington, New Zealand

Philip L. Pearce College of Business Law and Governance, James Cook University, Townsville, Australia

Harald Pechlaner Catholic University of Eichstaett-Ingolstadt, Eichstaett, Germany

Aurora Pedro Institute for International Economics, University of Valencia, Valencia, Spain

Victoria Peel Faculty of Arts, Monash University, Clayton, Australia

Paul Peeters Centre for Sustainable Tourism and Transport, NHTV Breda University of Applied Sciences, Breda, The Netherlands

Kennedy Calvin Craig Pemberton Research and Development, Mas Transformation Secretariat, St. Augustine, Trinidad and Tobago

Lori Pennington-Gray Department of Tourism, Recreation, and Sport Management, University of Florida, Gainesville, USA

Tomas Pernecky School of Hospitality and Tourism, University of Technology, Auckland, New Zealand

David Perrain Centre d'Economie et Management de l'Ocean Indien, St-Denis, Réunion, France

William P. Perry Cii Hotels and Resorts, (Pty) Ltd, Johannesburg, South Africa 
Mike Peters Department of Strategic Management, Marketing and Tourism, University of Innsbruck, MCI Management Center Innsbruck, Innsbruck, Austria

Lidija Petrić Faculty of Economics, University of Split, Split, Croatia

James F. Petrick Department of Recreation, Park, and Tourism Sciences, Texas A\&M University, College Station, USA

Christof Pforr School of Marketing, Curtin Business School, Curtin University, Perth, Australia

Pradech Phayakvichien Tourism Authority of Thailand, Bangkok, Thailand

Chris Phelan Lincoln Business School, University of Lincoln, Lincoln, UK

Kelly Virginia Phelan School of Business, The University of Queensland, Brisbane, QLD, Australia

Winston Phulgence Sir Arthur Lewis Community College, Castries, Saint Lucia

Pedro Pintassilgo Faculty of Economics and Research Center for Organizational and Spatial Dynamics, University of Algarve, Faro, Portugal

Hugo Pinto Centre for Social Studies, University of Coimbra, Coimbra, Portugal

Abraham Pizam Rosen College of Hospitality Management, University of Central Florida, Orlando, USA

Vincent Platenkamp Centre for Cross Cultural Understanding, NHTV University of Applied Sciences, Breda, The Netherlands

Ma Ángeles Plaza-Mejía Management and Marketing Department, Faculty of Business Studies, University of Huelva, Huelva, Spain

Clemente Polo Universidad Autónoma de Barcelona, Barcelona, Spain

Wilhelm Pompl International Business and Tourism Management, Heilbronn University, Heilbronn, Germany

Lauren M. Ponder South Carolina National Heritage Corridor, Spartanburg, USA

Nuria Porras-Bueno Management and Marketing Department, Faculty of Business Studies, University of Huelva, Huelva, Spain

Ana Portolan Department of Economics and Business Economics, University of Dubrovnik, Dubrovnik, Croatia

Surya Poudel School of Community Resources and Development, Arizona State University, Phoenix, AZ, USA

Stephanie Pougnet Ecole hôtelière de Lausanne, HES-SO University of Applied Sciences Western Switzerland, Lausanne, Switzerland 
Stephen Pratt School of Hotel and Tourism Management, The Hong Kong Polytechnic University, Hong Kong, China

Bruce Richard Prideaux School of Business and Law, Central Queensland University, Cairns, QA, Australia

Annette Pritchard Welsh Centre for Tourism Research, Cardiff Metropolitan University, Cardiff, UK

Vadim Pshtyka Immanuel Kant Baltic Federal University, Kaliningrad Oblast, Russia

Agustí García Puig Credit Andorra Bank, Andorra La Vella, Andorra

Ágnes Raffay Department of Tourism, Faculty of Economics, University of Pannonia, Veszprém, Hungary

Adla Ragab Cairo University, Oula, Egypt

Razaq Raj Carnegie Faculty, School of Events, Tourism and Hospitality, Leeds Beckett University, Leeds, UK

Patricia Rajeriarison Alter Ego Development, Antananarivo, Madagascar

Madhawi Ramdin Equal Chances at Green Development, Paramaribo, Suriname

Vicente Ramos Institute of Tourism and Sustainable Economic Development, Universidad de Las Palmas de Gran Canaria, Las Palmas de Gran Canaria, Spain

Zaharah Mohamed Rani Faculty of Hotel and Tourism Management, Universiti Teknologi MARA, Puncak Alam, Selangor, Malaysia

Mohammad Reza Rashidi Allameh Tabatabae'i University, Tehran, Iran

Fy Rasoamananjara University of Antananarivo, Betongolo Tana, Madagascar

Tamara Rátz Kodolányi János University of Applied Sciences, Budapest, Hungary

Syed Ali Raza Iqra University, Karachi, Pakistan

Francesco Redi Fondacioni Europa, Tirana, Albania

Dirk Reiser Cologne Business School, European University of Applied Sciences, Koeln, Germany

Yvette Reisinger College of Business Administration, Gulf University for Science and Technology, Mubarak Al-Abdullah, Kuwait

Paula Cristina Remoaldo Department of Geography, University of Minho, Institute of Social Sciences, Braga, Guimarães, Portugal

Carina Ren Department of Culture and Global Studies, Aalborg University, Copenhagen, Denmark 
Raquel García Revilla UDIMA Universidad a Distancia de Madrid, Collado

Villalba, Madrid, Spain

Javier Rey-Maquieira Institute of Tourism and Sustainable Economic Development, Universidad de Las Palmas de Gran Canaria, Las Palmas de Gran Canaria, Spain

Manuel Alector Ribeiro Faculty of Economics, University of Algarve, Faro, Portugal

José Cadima Ribeiro Department of Economics, University of Minho, School of Economics and Management, Braga, Portugal

Brendan M. Richard Rosen College of Hospitality Management, University of Central Florida, Orlando, FL, USA

Jillian M. Rickly Business School, The University of Nottingham, Nottingham, UK

Jorge Ridderstaat Central Bank of Aruba, Oranjestad, Aruba

Bradley Rink Department of Geography, Environmental Studies and Tourism, University of the Western Cape, Bellville, South Africa

Brent W. Ritchie UQ Business School, University of Queensland, St Lucia, Australia

Christian Ritter School of Sociology and Applied Social Studies, Ulster University, Londonderry/Derry, UK

Syed Ahmad Rizwan Centre for Tourism Research and Development, Tourism Recreation Research, Lucknow, Uttar Pradesh, India

Mike Robinson Ironbridge International Institute for Cultural Heritage, University of Birmingham, Edgbaston, Birmingham, UK

Richard N. S. Robinson Business School, University of Queensland, Brisbane, Australia

Marco Antonio Robledo Departamento de Economia de I'Empresa, Universitat de les Illes Balears, Palma de Mallorca, Spain

Brígida Rocha Brito Universidade Autónoma de Lisboa, Lisbon, Portugal

Rafael Rodríguez Acevedo Department of Technology Services, Universidad Simón Bolívar, Camurí Grande, Vargas, Venezuela

Wesley S. Roehl School of Tourism and Hospitality Management, Temple University, Philadelphia, USA

Marija Rok Faculty of Tourism Studies - Turistica, University of Primorska, Portoroz, Slovenia

Tania Paola Romero-Brito Griffith School of Environment, Griffith University, Gold Coast, Australia 
Jaume Rosselló Departament d'Economia Aplicada, Universitat de les Illes Balears, Palma de Mallorca, Spain

Sherif Roubi Assetreal Limited, Glasgow, UK

Diane Royal Department of Anthropology, Memorial University of Newfoundland, St. John's, Newfoundland, Canada

Lisa Ruhanen UQ Business School, The University of Queensland, St Lucia, Australia

Jarkko Saarinen Department of Geography, University of Oulu, Oulu, Finland

Noel B. Salazar Cultural Mobilities Research, University of Leuven, Leuven, Belgium

Clare A. Sammells Department of Sociology and Anthropology, Bucknell University, Lewisburg, PA, USA

Sandra M. Sánchez-Cañizares Faculty of Law and Business, University of Cordoba, Andalusia, Spain

Amparo Sancho Perez Instituto de Economía Internacional, University of Valencia, Valencia, Spain

Maria Santana Department of Applied Economics, Universitat de les Illes Balears, Palma de Mallorca, Spain

Agustín Santana-Talavera I.U. Ciencias Políticas y Sociales, University of La Laguna, Santa Cruz de Tenerife, Spain

Carla A. Santos Department of Recreation, Sport and Tourism, University of Illinois at Urbana-Champaign, Champaign, IL, USA

Sérgio P. Santos Faculty of Economics, University of Algarve, Faro, Portugal

João Sarmento University of Minho, Guimarães, Portugal

Martin Šauer Masaryk University, Brno, Czech Republic

Alexis Saveriades Department of Hotel and Tourism Management, Cyprus University of Technology, Limassol, Cyprus

Elaine Cristina Borges Scalabrini University of Minho, Braga, Portugal

Michael Scantlebury Hospitality and Tourism Management, Grand Valley State University, Allendale, MI, USA

Heike Schänzel School of Hospitality and Tourism, Auckland University of Technology, Auckland, New Zealand

Erica Schenkel National Council for Scientific and Technological Research, Sarmiento, Argentina

Knut Scherhag Worms University of Applied Sciences, Worms, Germany 
Nicolai Scherle International Management for Service Industries, BiTS Business and Information Technology School GmbH, Iserlohn, Germany

Regina Schlüter Universidad Nacional de Quilmes Bernal, Buenos Aires, Argentina

Marcus Schmidt Department of Marketing, Copenhagen Business School, Frederiksberg, Denmark

Marko Scholze Goethe University, Frankfurt, Germany

Markus Schuckert School of Hotel and Tourism Management, The Hong Kong Polytechnic University, Hong Kong, China

Fred R. Schumann School of Business and Public Administration, University of Guam, Mangilao, USA

David Scott School of Business and Tourism, Southern Cross University, East Lismore, Australia

Mary Katherine Scott Art History, University of Wyoming, Laramie, USA

Noel Scott Griffith Institute for Tourism, Griffith University, Gold Coast, QLD, Australia

Boopen Seetanah Department of Finance and Accounting, Faculty of Law and Management, University of Mauritius, Reduit, Mauritius

Tom Selänniemi Corporate Relations, Finnish Committee for UNICEF, Helsinki, Finland

Tom Selwyn Department of Anthropology and Sociology, SOAS University of London, London, UK

Askar Mukashev Serikboluly AEO, Nazarbayev Intellectual Schools, Astana, Kazakhstan

Francisco Serra School of Management, Hospitality and Tourism, University of Algarve, Faro, Portugal

Delphine Le Serre ISTEC Business School, Paris, France

Aishath Shakeela Department of Tourism, Sport and Hotel Management, Griffith University, Queensland, Australia

Tekle Shanka School of Marketing, Curtin Business School, Curtin University, Perth, Australia

Valeriya Shapoval Rosen College of Hospitality Management, University of Central Florida, Orlando, USA

Richard Sharpley School of Management, University of Central Lancashire, Preston, Lancashire, UK

Ahmad Reza Sheikhi University of La Laguna, Tenerife, Spain

Pauline J. Sheldon School of Travel Industry Management, University of Hawai'i at Manoa, Honolulu, USA 
Eric J. Shelton Department of Tourism, University of Otago, Dunedin, New Zealand

Han Shen Tourism Department, Fudan University, Shanghai, China

Alec Sherman School of Hotel Administration, Cornell University, Ithaca, USA

Changsup Shim Department of Tourism Management, Gachon University, Seongnam-si, Gyeonggi-do, South Korea

Qobiljon Shokirov University of Central Asia, Khorog, Tajikistan

Wilson Silungwe Hotel and Tourism Training Institute, Maluba, Zambia

David Simmons Faculty of Environment, Society and Design, Lincoln University, Lincoln, Canterbury, New Zealand

Gaunette Sinclair-Maragh School of Hospitality and Tourism Management, College of Business and Management, University of Technology, Kingston, Jamaica

Sagar Singh Centre for Tourism Research and Development, Tourism Recreation Research, Lucknow, Uttar Pradesh, India

Shalini Singh Department of Recreation and Leisure Studies, Brock University, St. Catharines, ON, Canada

Agnes Sirima Sokoine University of Agriculture, Morogoro, Tanzania

Geoffrey Skoll Criminal Justice Department, Buffalo State College, Buffalo, USA

Stephen L. J. Smith School of Hospitality, Food, and Tourism Management, University of Guelph, Guelph, ON, Canada

Wayne W. Smith College of Charleston, Charleston, USA

Bernardin Solonandrasana University of Perpignan, Perpignan, France

Haiyan Song School of Hotel and Tourism Management, The Hong Kong Polytechnic University, Hong Kong, China

Anders Sørensen TourismLab.dk, Roskilde, Denmark

Beverley Sparks Department of Tourism, Sport and Hotel Management, Griffith University, Nathan, Australia

Daniel L. Spears College of Merchandising, Hospitality and Tourism, University of North Texas, Denton, USA

Michael Spisto College of Law and Justice, Victoria University, Melbourne, Australia

Hasso Spode Historical Archive on Tourism, Technische Universität Berlin, Berlin, Germany 
Aurelia-Felicia Stăncioiu The Bucharest University of Economic Studies, Bucharest, Romania

Albrecht Steinecke University of Paderborn, Paderborn, Germany

Rochelle Steven Environmental Futures Research Institute, Griffith University, Nathan, QLD, Australia

Emma J. Stewart Faculty of Environment, Society and Design, Lincoln University, Lincoln, New Zealand

Lesego S. Stone Okavango Research Institute, University of Botswana, Maun, Botswana

Moren T. Stone Department of Environmental Science, University of Botswana, Gaborone, Botswana

Philip Stone Institute for Dark Tourism Research, University of Central Lancashire, Preston, Lancashire, UK

Lars Strannegård Department of Management and Organization, Stockholm School of Economics, Stockholm, Sweden

Michael C. Sturman School of Hotel Administration, Cornell University, Ithaca, USA

Ming Ming Su School of Environment and Natural Resources, Renmin University of China, Beijing, China

Wantanne Suntikul School of Hotel and Tourism Management, The Hong Kong Polytechnic University, Hong Kong, China

Margaret Byrne Swain Department of Women and Gender Studies, University of California, Davis, USA

Jason R. Swanson Department of Retailing and Tourism Management, University of Kentucky, Lexington, USA

Kazuyoshi Takeuchi English Communication, Jissen Women's Junior College, Shibuya-ku, Tokyo, Japan

Victor Teye The School of Community Resources and Development, Arizona State University, Phoenix, USA

Reginah Marankopane Thetsane Department of Business Administration, National University of Lesotho, Roma, Lesotho

Daniela Fernanda Thiel-Ellul School of Economics and Business, National University of San Martín, San Martín, Buenos Aires, Argentina

Guillaume Tiberghien School of Hospitality and Tourism, Auckland University of Technology, Auckland, New Zealand

Dallen J. Timothy School of Community Resources and Development, Arizona State University, Phoenix, AZ, USA 
Dolores Tirado Bennasar Universitat de les Illes Balears, Palma de Mallorca, Spain

Oksana Tokarchuk School of Economics and Management, Free University of Bolzano-Bozen, Bolzano, Italy

Denis Tolkach School of Hotel and Tourism Management, The Hong Kong Polytechnic University, Hong Kong, China

Pooneh Torabian Department of Recreation and Leisure Studies, University of Waterloo, Waterloo, ON, Canada

Bartolomé Deya Tortella Business Economics Department, University of Balearic Islands, Palma de Mallorca, Spain

Mika Toyota College of Tourism, Rikkyo University, Niiza-shi, Saitama, Japan

J. Bruce Tracey School of Hotel Administration, Cornell University, Ithaca, USA

Raúl Travé-Molero Ciencias Sociales y Humanas, University Miguel Hernández de Elche, Elche, Spain

Magnus Treiber Department of Anthropology, University of Bayreuth, Bayreuth, Germany

John Tribe School of Hospitality and Tourism Management, University of Surrey, Guildford, UK

V. Dao Truong National Economics University, Hanoi, Vietnam

Michael K. Tschapka Institut für Angewandte Forschung, Ostbayerische Technische Hochschule Amberg, Weiden, Germany

Tony Tse School of Hotel and Tourism Management, The Hong Kong Polytechnic University, Hong Kong, China

Eliza Ching-Yick Tse Department of Hospitality Management, University of Missouri, Columbia, USA

Eddy K. Tukamushaba Stenden University Qatar, Doha, Qatar

Elena Turcov The Academy of Economic Studies of Moldova, Chișinău, Moldova

Rodanthi Tzanelli School of Sociology and Social Policy, Faculty of Education, Social Sciences and Law, University of Leeds, West Yorkshire, UK

Alexia Mary Tzortzaki Department of Accounting and Finance, Technological Educational Institute of Crete, Heraklion, Greece

Jorge Umbelino Escola Superior de Hotelaria e Turismo do Estoril, Estoril, Portugal

Akarapong Untong School of Tourism Development, Maejo University, Chiang Mai, Thailand 
Amitabh Upadhya Skyline University College, University City of Sharjah, Sharjah, United Arab Emirates

Randall Upchurch Chaplin School of Hospitality and Tourism Management, Florida International University, Miami, USA

Natan Uriely Department of Hotel and Tourism Management, Ben Gurion University of the Negev, Beersheba, Israel

Muzaffer Uysal Hospitality and Tourism Management, Virginia Polytechnic Institute and State University, Blacksburg, USA

Elisabeth Valle Department of Applied Economics, Universitat de les Illes Balears, Palma de Mallorca, Spain

René Van der Duim Department of Environmental Sciences, Wageningen University, Wageningen, The Netherlands

Robert van der Veen Faculty of Business, Oxford Brookes University, Oxford, UK

Pierre L. van den Berghe Department of Sociology, University of Washington, Seattle, USA

Mathilda van Niekerk Rosen College of Hospitality Management, University of Central Florida, Orlando, USA

Johan van Rekom RSM Erasmus University, Rotterdam, The Netherlands

Manuel Vanegas Sr Department of Applied Economics, St. Paul, University of Minnesota, Minneapolis, USA

Norbert Vanhove Brugge, Belgium

Alfonso Vargas-Sánchez Management and Marketing Department, Faculty of Business Studies, University of Huelva, Huelva, Spain

Magiel Venema NHTV Breda University of Applied Sciences, Breda, The Netherlands

Dominique Verdugo Tourism and Protected Areas Specialist Group, Sustainable Tourism Development, Bordeaux, France

Philippe Viallon University of Strasbourg, Strasbourg, France

Dumsile Vilakati University of Swaziland, Manzini, Swaziland

Christine A. Vogt School of Community Resources and Development, Arizona State University, Phoenix, AZ, USA

Michael Volgger Institute for Regional Development and Location Management, European Academy Bozen, Bolzano, Italy

Serena Volo Faculty of Economics and Management, TOMTE, Free University of Bozen-Bolzano, Bolzano, Italy

Manuel Vong Tourism and Hospitality, Dili Institute of Technology, Dili, Timor-Leste 
Fanny Vong Institute for Tourism Studies, Macao, China

Aleksa Vučetić The Faculty of Tourism and Hospitality, The University of Montenegro, Kotor, Montenegro

Geoffrey Wall Department of Geography, University of Waterloo, Waterloo, ON, Canada

Tim Wallace Department of Sociology and Anthropology, North Carolina State University, Raleigh, NC, USA

Daisy Wang Department of Business Management, College of Business and Management, East Stroudsburg University, East Stroudsburg, USA

Dan Wang School of Hotel and Tourism Management, The Hong Kong Polytechnic University, Hong Kong, China

Ning Wang Department of Sociology, Sun Yat-Sen University, Guangzhou, China

Yi Wang University of Nottingham Ningbo, China

Youcheng Wang Rosen College of Hospitality Management, University of Central Florida, Orlando, USA

Stephen Wanhill University of Limerick, Limerick, Ireland

James F. Wani DanChurchAid, Juba, South Sudan

Colleen Ward School of Psychology, Victoria University of Wellington, Kelburn Pde, New Zealand

Philipp Wassler School of Hotel and Tourism Management, The Hong Kong Polytechnic University, Hong Kong, China

Stephen L. Wearing University of Technology Sydney, Sydney, Australia

Adam Weaver School of Management, Victoria University of Wellington, Wellington, New Zealand

David Weaver Department of Tourism, Sport and Hotel Management, Griffith University, Gold Coast, Australia

Karin Weber School of Hotel and Tourism Management, The Hong Kong Polytechnic University, Hong Kong, China

Clare Weeden School of Sport and Service Management, University of Brighton, Eastbourne, UK

Klaus Weiermair Center for Tourism and Service Economics, University of Innsbruck, Stock Ost, Innsbruck, Austria

William B. Werner Harrah College of Hotel Administration, University of Nevada, Las Vegas, USA

Allan M. Williams School of Hospitality and Tourism Management, University of Surrey, Guildford, UK 
Deanne Williams-Bryant Department of Hospitality Management, Virginia State University, Petersburg, USA

Cedric Wilson Department of CARICOM, Caribbean Renewable Energy Project, University of the West Indies, Bridgeview, Jamaica

Erica Wilson School of Business and Tourism, Southern Cross University, East Lismore, Australia

Caroline Winter The Business School, Federation University Australia, Mt Helen, Australia

Tim Winter Alfred Deakin Research Institute for Citizenship and Globalisation, Deakin University, Melbourne, Australia

Agung Suryawan Wiranatha Tourism Study and Research Center, Udayana University, Denpasar City, Bali, Indonesia

Nicholas Wise Glasgow School for Business and Society, Glasgow Caledonian University, Glasgow, Lanarkshire, UK

Cordula Wohlmuther Centre for Peace Research and Peace Education, Adriatic University Klagenfurt, Klagenfurt, Austria

Cora Un In Wong Institute for Tourism Studies, Macao, China

Marta Wood Institute of Tourism and Sustainable Economic Development, Universidad de Las Palmas de Gran Canaria, Las Palmas de Gran Canaria, Spain

Robert H. Woods William F. Harrah College of Hotel Administration, University of Nevada-Las Vegas, Las Vegas, USA

Arch G. Woodside Marketing Department, Boston College, Chestnut Hill, USA

Bihu Wu College of Urban and Environmental Sciences, Peking University, Beijing, China

Qu Xiao School of Hotel and Tourism Management, The Hong Kong Polytechnic University, Hong Kong, China

Philip F. Xie Faculty of Hospitality and Tourism Management, Macao University of Science and Technology, Macao, China

Honggang Xu School of Tourism Management, Sun Yat-sen University, Guangzhou, China

Lan Xue Department of Recreation, Park and Tourism Management, The Pennsylvania State University, University Park, USA

Kamil Yagci Faculty of Tourism, Department of Travel Management and Tourism Guidance, Pamukkale University, Denizli, Turkey

Shinji Yamashita Department of Cultural Anthropology, The University of Tokyo, Meguro-ku, Tokyo, Japan 
Libo Yan Macao University of Science and Technology, Macao, China

Hongliang Yan Carnegie Faculty, School of Events, Tourism and Hospitality, Leeds Beckett University, Leeds, UK

Li Yang Department of Geography, Western Michigan University, Kalamazoo, USA

Jingjing Yang School of Hospitality and Tourism Management, University of Surrey, Guildford, UK

Tianyu Ying Department of Tourism, University of Otago, Dunedin, New Zealand

Mohammad Youssef Expert Tourism Affairs, National Council of Tourism and Antiquities, Dubai, United Arab Emirates

Alvin HungChih Yu Department of Geography, St Cloud State University, St Cloud, USA

Dongkoo Yun Centre for Tourism Research, Charlottetown, Prince Edward Island, Canada

Fidel Ernesto Zablah Department of Business Administration, Universidad Centroamericana José Simeón Cañas, San Salvador, El Salvador

Vincent Zammit Centre for Cultural and Heritage Studies, Institute of Tourism Studies, St Julian's, Malta

Hamid Zargham Department of Tourism Management, Faculty of Management and Accounting, University of Allameh Tabataba'i University (ATU), Tehrān, Iran

Bojan Zecevic Faculty of Economics, University of Belgrade, Belgrade, Serbia

Aihua Zhang Department of History, The State University of New York at Stony Brook, NY, USA

Guangrui Zhang Tourism Research Centre, Chinese Academy of Social Sciences, Beijing, China

Hanqin Qiu Zhang School of Hotel and Tourism Management, The Hong Kong Polytechnic University, Hong Kong, China

Jie Zhang Centre for Regional and Tourism Research, Nexø, Denmark

Jie Zhang Nanjing University, Nanjing, China

Jinhe Zhang Nanjing University, Nanjing, China

Jundan Jasmine Zhang Department of Tourism, University of Otago, Dunedin, New Zealand

Lingyun Zhang Tourism Institute, Beijing Union University, Beijing, China

Shengnan Zhao Department of Recreation and Leisure Studies, California State University, Long Beach, CA, USA 
Weibing Zhao Institute for Tourism Studies, Macao, China

Xiangmin Zheng College of Tourism, Huaqiao University, Quanzhou, Fujian, China

Zongqing Zhou College of Hospitality and Tourism Management, Niagara University, NY, USA

Yujie Zhu Australian Centre on China in the World, Australian National Univeristy, Canberra, ACT, Australia

Andreas H. Zins Department of Tourism and Service Management, Modul University Vienna, Vienna, Austria

Yongguang Zou College of Tourism, Huaqiao University, Quanzhou, Fujian, China

Hugo Marcelo Zunino Department of Social Sciences, Universidad de la Frontera, Temuco, Chile 
